\title{
An intelligent lead-acid battery closed-loop charger using a combined fuzzy controller for PV applications
}

\author{
Iliass Rkik ${ }^{1, *}$, Mohamed El khayat ${ }^{1}$, Hafsa Hamidane $^{1,}$, Abdelali Ed-Dahhak ${ }^{1,}$, Mohammed Guerbaoui ${ }^{1,}$, and Abdeslam \\ Lachhab $^{1,}$ \\ ${ }^{1}$ Modelling, Materials and Systems Control Team, Higher school of Technology, Moulay Ismail University of Meknes, Morocco. \\ ESTM Km 5, Rue d'Agouray, P1, Meknes 50040.
}

\begin{abstract}
This paper presents the modeling of an intelligent combined MPPT and Lead-Acid battery charger controller for standalone solar photovoltaic systems. It involves the control of a DC/DC buck converter through a control unit, which contains two cascaded fuzzy logic controllers (FLC), that adjusts the required duty cycle of the converter according to the state of charge and the three stage lead acid battery charging system. The first fuzzy logic controller (FLC1) consists of an MPPT controller to extract the maximum power produced by the PV array, while the second fuzzy controller (FLC2) is aimed to control the voltage across the battery to ensure the three stage charging approach. This solution of employing two distinct cascaded fuzzy controllers surmounts the drawbacks of the classical chargers in which the voltage provided to the lead acid battery is not constant owing to the effects of the MPPT control which can automatically damage the battery. Thus, the suggested control strategy has the benefit of extracting the full power against the PV array, avoiding battery damage incurred by variable MPPT voltage and increasing the battery's lifespan.
\end{abstract}

\section{Introduction}

Batteries power supply and their charge control systems have generally been recognized as the heart of PV applications [1]. In this context batteries must have a good cycling efficiency and an effective depth of discharge level.As more of a bridge between the PV array and the load, a DCDC converter is always used, with its duty cycle varies to ensure that the PV panel performs at the maximum power point(MPP).

In the literature, various strategies of the maximum power point tracking (MPPT) have been carried out, that can be ranked into the following classification[2],[3]: classical MPPT techniques, MPPT strategies on the basis of Artificial Intelligence (AI), and MPPT techniques based linear and non-linear controllers [4]. Among the most widely used MPPT techniques, namely the classical Perturb and Observe ( $\mathrm{P} \& \mathrm{O})$ Algorithm, incremental conductance (IncC), neuro-fuzzy and neural network methods $[5,6]$. Many researchers are involved in the fuzzy-logiccontroller based MPPT strategy [7],[8],[10]. In this way, it has been confirmed that the Fuzzy Logic (FL) control technique-based MPPT outperforms the traditional MPPT techniques under variable weather conditions in terms of robustness and accuracy [9].

In this paper, two cascaded fuzzy controllers are used to increase the system's efficiency and accuracy. The first one FLC1 is responsible to extract the MPP from the PV array, in the other hand, another fuzzy logic controller FLC2 is used for the purpose of performing as a lead-acid bat-

*e-mail: rkik.iliass@gmail.com/iliass.rkik@edu.umi.ac.ma tery charge controller, in order to avoid battery damage incurred by variable MPPT voltage and increasing the battery's lifespan.

Therefore, this control strategy maximises the power provided by the PV array, extends the battery's life cycle by preventing the overcharge incurred by the MPPT controller and mitigates the disadvantages and limitations of the traditional solar chargers.

\section{Methodology}

Figure 1 describes the schematic diagram of the standalone photovoltaic based MPPT battery charge controller system, which is developed in Matlab/Simulink ${ }^{T M}$. The system is composed of a PV array linked directly to the DC connection, as well as an integrated power buck converter connected to a lead acid (Le-A) battery. An MPPT charge block controller is composed of two fuzzy systems, the first one is the FLC1 includes a fuzzy logic block based MPPT controller,it is used to extract the full amount of power supplied by the photovoltaic generator. The second stage of the controller is another fuzzy voltage regulator block (FLC2) based on the three stage-charging technique, which ensures the regulation of the voltage across the LeA battery.

\subsection{PV Modeling}

A solar photovoltaic cell is composed effectively of a PN semiconductor-junction that transforms illumination energy to electrical energy [11]. The solar cell can be illus- 
Table 1. SY-270W panel's parameters

\begin{tabular}{|l|c|r|}
\hline PV Data & Unit & Value \\
\hline Maximum power & $\mathrm{W}$ & 270 \\
Current at the MPP & $\mathrm{A}$ & $7.44 \mathrm{~A}$ \\
Voltage at the MPP & $\mathrm{V}$ & 36.28 \\
Open-Circuit Voltage & $\mathrm{V}$ & 43.63 \\
Short-Circuit Current & $\mathrm{A}$ & 7.96 \\
\hline
\end{tabular}

trated by a voltage-controlled current source that presents the temperature and solar emission sensitive, in parallel with one diode and a shunt-resistor Rsh and in series with a connected resistor Rs [12]. After being a simplistic model, this analogous circuit is precise enough to reflect the various forms of photovoltaic cells. the numerical analysis of solar cells is described in depth in [13]. Figure 2 presents a single diode model configuration .

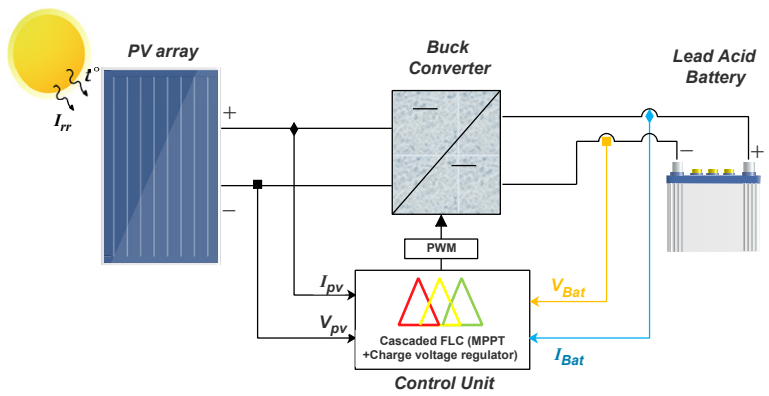

Figure 1. PV battery charger control diagram

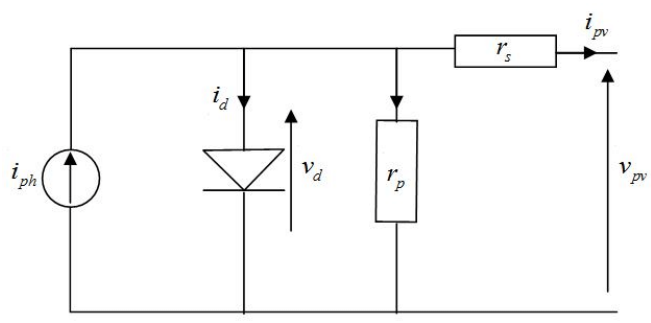

Figure 2. Photovoltaic Cell

As light comes upon it, the PV panel functions as a current source, PV array are a series-parallel combination of solar cells. In This context, the PV array used in this research consists of eight (SY-270W) Shenzhen Sunshine module connected in series as shown in the figure 3 . The parameters of the used module are presented in Table 1.

A design for the industrial used module has been developed in order to achieve more practical conditions for the performed simulations.

The SY-270W PV module charachteristic is illustrated in figure 4 at a various amounts of irradiation and temperature.

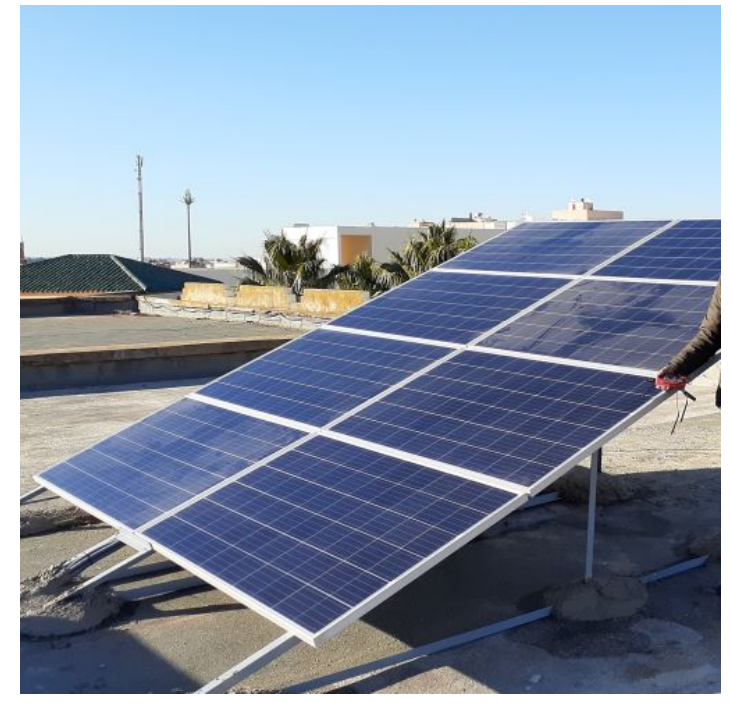

Figure 3. Photovoltaic panels installed in the laboratory
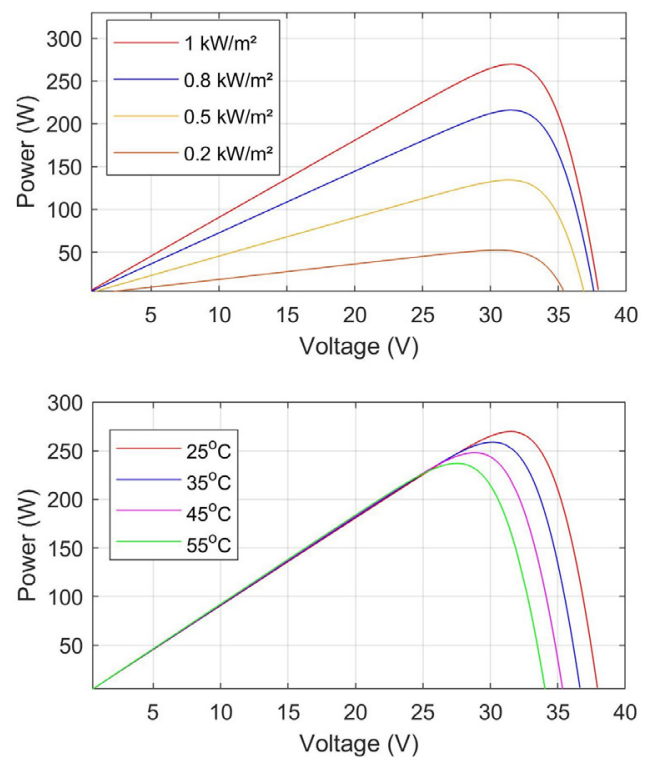

Figure 4. PV curves of SY-270W

\subsection{DC/DC Buck converter Modeling}

The buck converter was preferred in order to transform and regulate the high supply voltage into the required low Lead battery voltage[14]. The figure 5 corresponds to the average model of the DC-DC buck converter on the basis of the internal and output capacitors Cin and Co. $\mathrm{S}$ and $\mathrm{L}_{b}$ are respectively the controlled mosfet and the inductance, where the input/output voltages are respectively Vin \& Vout. The buck parameters are calculated as follow:

$$
\begin{gathered}
V_{\text {out }}=V_{\text {in }} \times D \\
L_{b}=V_{\text {out }} \frac{1-D}{\Delta I \times f}
\end{gathered}
$$




$$
C=V_{\text {out }} \frac{1-D}{8 f \times L_{b} \times \Delta V_{\text {out }}}
$$

Ripples in the output voltage and the amount current ripples in the inductor are commonly named $\Delta I$ and $\Delta V_{\text {out }}$.

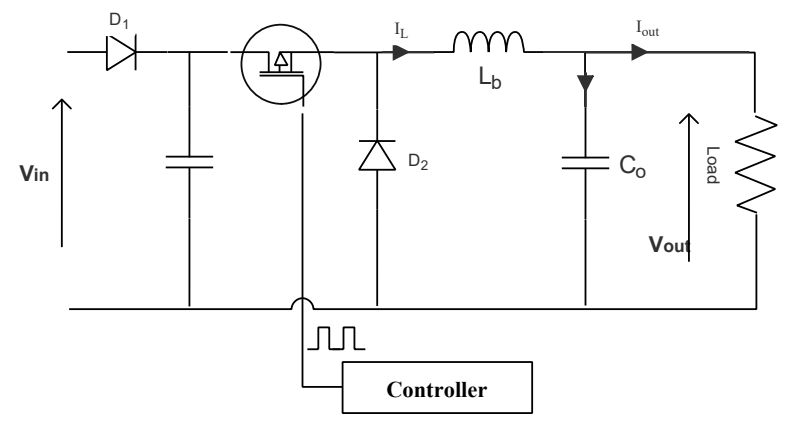

Figure 5. Buck design

\subsection{Le-Acid Battery design}

Thanks to their verified stability, high performance and abundance in various sizes, and lower cost, Le-Acid batteries are the most commonly installed storage devices in the $\mathrm{PV}$ applications [15],[16]. A parallel resistance and capacitance $\mathrm{R} 1 / / \mathrm{C} 1$ linked to an internal resistance $\mathrm{R}_{2}$ in series with a voltage source are the contents of the Thevenin related circuit design of Le-A battery as shown in figure 6 .

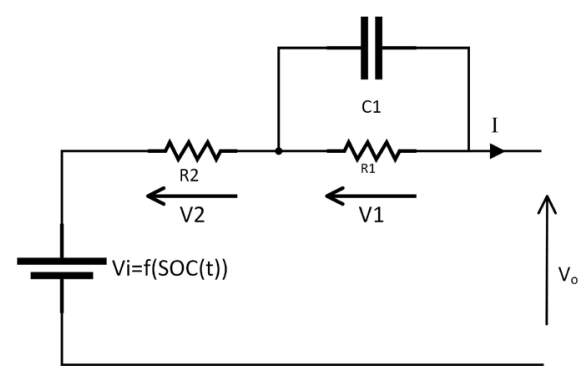

Figure 6. Le-Acid battery model

\section{Control strategy}

This section presents the approved control management given in this paper, and it is about the control unit which contains two cascaded-Fuzzy-Logic controllers.

\subsection{Le-Acid Battery Charging control}

A control design methodology must be applied in order to achieve a stable, full and quick Le-A battery charging operation. The design of the charge controller proposed in this paper is based on the DIN 41773 standard that offers three charging stages [17], which are: Bulk, absorption and float stages as shown in figure 7 . The first stage consists of the bulk charge, in this state, the first effective FLC act to extract the maximum power of the PV panel, in this way, the Le-A battery is charged via a constant current up to 80 of the SOC. During the bulk process and for the purpose of escaping premature battery wear and excessive heating, the battery current is restricted to the permitted maximum charging current $I_{(B-M A X)}$. The battery voltage starts to reach the absorption voltage $V_{(b-a s)}$, to prevent the over-voltage, the second FLC stage is involved in this phase (absorption) to adjust the battery voltage at $V_{(b-a s)}$, which allows to keep the charging process at the steady voltage $V_{(b-a s)}$. The battery power at this point is normally restored around $90 \%$. The full charge voltage is always determined by the constructor. In the absorption region, the charging current reduces until the battery is charged completely, where $I_{(B a t)}=I_{(B-\min )}$. Once the battery has reached $100 \%$ of its SoC, the voltage charging is decreased to its float voltage $V_{(b-f l)}$ where this region is called the Float Stage, at this phase, the float voltage $V_{(b-f l)}$ reference produces a very low float current $I_{(b-f l)}$ which is sufficient to offset self-discharge and the full load charge control.

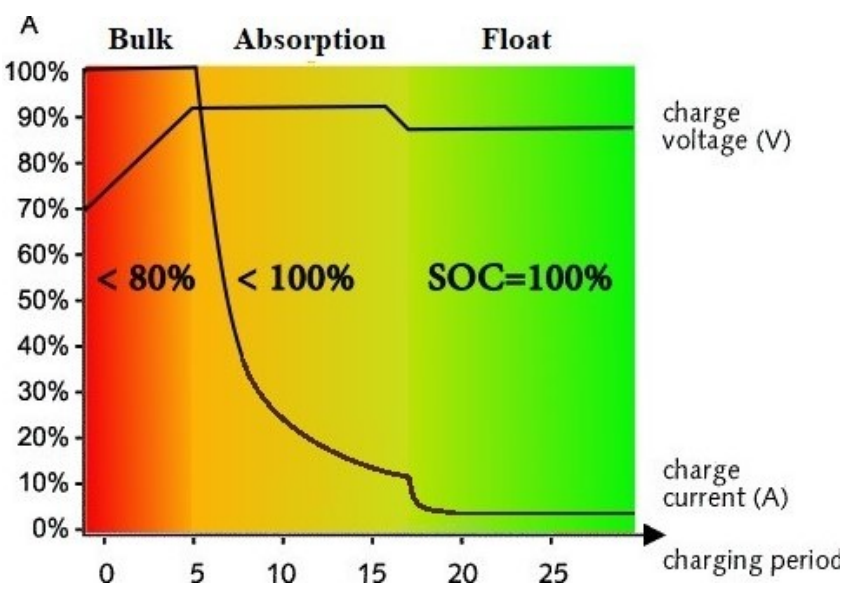

Figure 7. three stages Le-Acid battery charging process

\subsection{Description of the fuzzy logic controllers}

\subsubsection{First fuzzy logic stage based MPPT}

Currently, MPPT-based Fuzzy-Logic controller has become a suitable strategy of control for PV systems. The Fuzzy control approach needs no accurate model awareness, and it consists of three steps: (fuzzification, fuzzy rules and defuzzification) [18]. The controller's inputs are always the combination of the error and error variation. In the fuzzification stage, input parameters are transformed on the basis of several specified member functions into linguistic variables, the next stage (fuzzy rules) involves manipulation of these linguistic factors which are presented in the tables 2 and 3 , relying on laws based on the if $\&$ then principle that are driven by the system's ideal behaviour. In the final phase (defuziffication), the FLC control transforms linguistic variables on the output of membership 
Table 2. First FLC based MPPT rules

\begin{tabular}{|c|c|c|c|c|c|c|}
\hline & \multicolumn{5}{|c|}{$\zeta$} \\
\hline & & $\mathrm{P}, \mathrm{B}$ & $\mathrm{P}, \mathrm{S}$ & $\mathrm{ZE}$ & $\mathrm{N}, \mathrm{S}$ & $\mathrm{N}, \mathrm{B}$ \\
\hline \multirow{5}{*}{$\Delta \zeta$} & $\mathrm{P}, \mathrm{B}$ & $\mathrm{ZE}$ & $\mathrm{ZE}$ & $\mathrm{N}, \mathrm{B}$ & $\mathrm{N}, \mathrm{B}$ & $\mathrm{N}, \mathrm{B}$ \\
\hline & $\mathrm{P}, \mathrm{S}$ & $\overline{\mathrm{ZE}}$ & $\mathrm{ZE}$ & $\mathrm{N}, \mathrm{S}$ & $\mathrm{N}, \mathrm{S}$ & $\mathrm{N}, \mathrm{S}$ \\
\hline & $\mathrm{ZE}$ & $\mathrm{N}, \mathrm{S}$ & ZE & $\mathrm{ZE}$ & $\mathrm{ZE}$ & $\mathrm{P}, \mathrm{S}$ \\
\hline & $\mathrm{N}, \mathrm{S}$ & $\mathrm{P}, \mathrm{S}$ & $\overline{\mathrm{P}, \mathrm{S}}$ & $\mathrm{N}, \mathrm{S}$ & $\overline{\mathrm{ZE}}$ & $\mathrm{ZE}$ \\
\hline & $\mathrm{N}, \mathrm{B}$ & $\mathrm{P}, \mathrm{B}$ & $\mathrm{P}, \mathrm{B}$ & $\mathrm{P}, \mathrm{B}$ & $\mathrm{ZE}$ & $\mathrm{ZE}$ \\
\hline
\end{tabular}

functions to numerical variables. The following equations presents the two Inputs of the first controller FLC1 designed for MPPT:

$$
\begin{gathered}
\zeta(n)=\frac{\delta P}{\delta V}=\frac{P_{(n)}-P_{(n-1)}}{V_{(n)}-V_{(n-1)}} \\
\Delta \zeta(n)=\zeta_{(n)}-\zeta_{(n-1)}
\end{gathered}
$$

The output is the difference in the duty cycle $D_{k}$ that changes obviously the DC-DC converter efficiency as a result in the Equation 6:

$$
\Delta D_{k}=\frac{\sum_{i}^{n} A_{i} Y_{i}}{\sum_{i}^{n} A_{i}} \delta \zeta_{k}
$$

Where, $\zeta_{k}$ is the slop power Ppv and voltage Vpv curve change, $\Delta \zeta_{k}$ is the change of $\zeta_{k}$, and the minimum of membership is $\mathrm{Ai}$ where $\mathrm{Ai}=\min$ [Memberships \& rules] .

The five subsets memberships used in the FLC 1 are positive big, positive small, zero, negative small and negative big respectively $\mathrm{P}, \mathrm{B}-\mathrm{P}, \mathrm{S}-\mathrm{ZE}-\mathrm{N}, \mathrm{S}$ and N,B.

\subsubsection{Second fuzzy logic stage based voltage regulator}

This phase controls the battery output voltage with the usual voltage of the DC/DC buck converter through the second fuzzy logic unit named FLC2, which uses as inputs the error $\zeta^{\prime}$ and the error change $\Delta \zeta^{\prime}$ of the voltage difference across the battery as shown in the following equations:

$$
\begin{gathered}
\zeta^{\prime}{ }_{(n)}=V_{R E}(n)-V_{B}(n) \\
\Delta \zeta^{\prime}{ }_{(n)}=\zeta_{(n)}^{\prime}-\zeta^{\prime}{ }_{(n-1)} \\
\Delta D^{\prime}{ }_{n+1}=F L C_{2}\left[\zeta^{\prime}{ }_{(n)}\right]
\end{gathered}
$$

Where $\mathrm{V}_{R E}$ is the needed charging voltage, $\Delta D^{\prime}{ }_{n+1}$ is the output of the FLC2 .

\begin{tabular}{|c|c|c|c|c|c|c|}
\hline & \multicolumn{5}{|c|}{$\zeta^{\prime}$} \\
\hline & & $\mathrm{N}, \mathrm{B}$ & $\mathrm{N}, \mathrm{M}$ & $\mathrm{ZE}$ & $\mathrm{P}, \mathrm{M}$ & $\mathrm{P}, \mathrm{B}$ \\
\hline \multirow{5}{*}{$\Delta \zeta^{\prime}$} & $\mathrm{P}, \mathrm{B}$ & $\mathrm{N}, \mathrm{B}$ & $\mathrm{N}, \mathrm{B}$ & $\mathrm{N}, \mathrm{B}$ & $\mathrm{ZE}$ & $\mathrm{ZE}$ \\
\hline & $\mathrm{P}, \mathrm{M}$ & $\mathrm{N}, \mathrm{M}$ & $\mathrm{N}, \mathrm{M}$ & $\mathrm{N}, \mathrm{M}$ & $\mathrm{ZE}$ & $\mathrm{ZE}$ \\
\hline & $\mathrm{ZE}$ & $\mathrm{P}, \mathrm{M}$ & $\overline{\mathrm{ZE}}$ & $\overline{\mathrm{ZE}}$ & $\mathrm{ZE}$ & $\overline{\mathrm{N}, \mathrm{M}}$ \\
\hline & $\mathrm{N}, \mathrm{M}$ & ZE & $\mathrm{ZE}$ & $\mathrm{N}, \mathrm{M}$ & $\mathrm{P}, \mathrm{M}$ & $\mathrm{P}, \mathrm{M}$ \\
\hline & N,B & $\mathrm{ZE}$ & $\mathrm{ZE}$ & $\mathrm{P}, \mathrm{B}$ & $\mathrm{P}, \mathrm{B}$ & $\mathrm{P}, \mathrm{B}$ \\
\hline
\end{tabular}

\section{Results and discussion}

In this paper, MATLAB/Simulink ${ }^{T M}$ software was used to design and model the entire structure depicted in the scheme presented in the first section. Table 1 lists the
Table 3. Second FLC2 based voltage controller rules

numerical values of the SPV panel used in the simulation with a peak power of $270 \mathrm{~W}$. The improved cascaded charge controllers based on FL control are presented in the previous section, they control directly the power DC/DC buck converter. The behaviour and reliability of the cascaded controllers are examined and evaluated.

\subsection{First FLC MPPT stage}

The first stage of the cascaded FL control is investigated by the presented solar irradiance profile in the figure 8 , and it varies between $0-1000 \mathrm{~W} / \mathrm{m}^{2}$. The brusque change in solar insolation profile was divided for this rigorous study into six states. The atmospheric temperature is constant at $25^{\circ} \mathrm{C}$. The efficiency and the behaviour of the first stage FLC1 were determined and compared with two common traditional MPPT methods: P\&O and IncCond [19]. The efficiency is determined according to the following equation:

$$
\eta=\int_{0}^{t} P_{\text {array }} \frac{1}{\int_{0}^{t} P^{\prime} M P P T} \times 100
$$

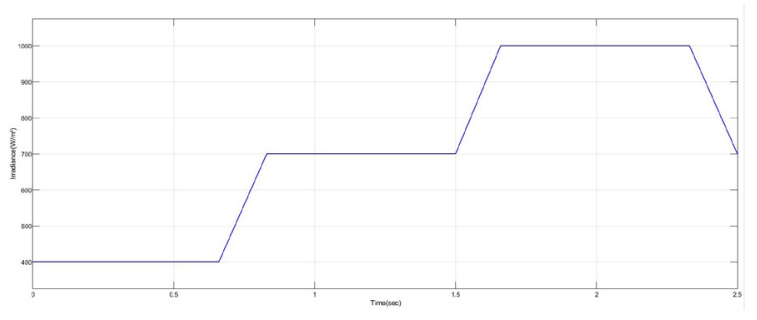

Figure 8. Irradiance profile

Figure 9 demonstrates the performance for each irradiance state of the compared MPPT strategies, Table 4 summarizes the results obtained for the different controllers. It can be observed that the FLC1-MPPT gives a better result in terms of dynamic response and power ripples compared to the other MPPT controllers.

\subsection{Second FLC charge controller stage}

The battery charge controller's output is demonstrated by charging the battery sequentially through bulk stage, absorption stage, and float charging level. This demonstrates 
Table 4. Comparison of the performance for the MPPT controllers at STC

\begin{tabular}{|c|l|l|l|}
\cline { 2 - 4 } \multicolumn{1}{c|}{} & P \& O & FLC1 & IncCond \\
\hline$\tau$ Rising time(s) & 0.188 & 0.12 & 0.202 \\
\hline Power ripples(w) & 0.8 & 0.07 & 0.62 \\
\hline Efficiency \% & 99.81 & 99.91 & 99.88 \\
\hline
\end{tabular}

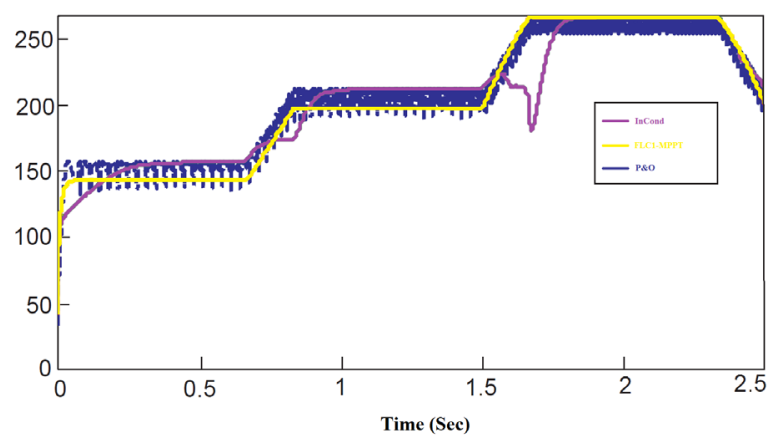

Figure 9. Power extracted of the SY-270W with different controller

the Le-A battery's three-stages charging levels. The PV array used in this paper includes eight SY-270W Shenzhen Sunshine panels ( 4 modules connected in series x 2 modules connected in parallels) which provides $2160 \mathrm{~W}$ at the STC. The PV array is also tested under solar irradiance variation and constant temperature as seen in the figures 10 and 11.

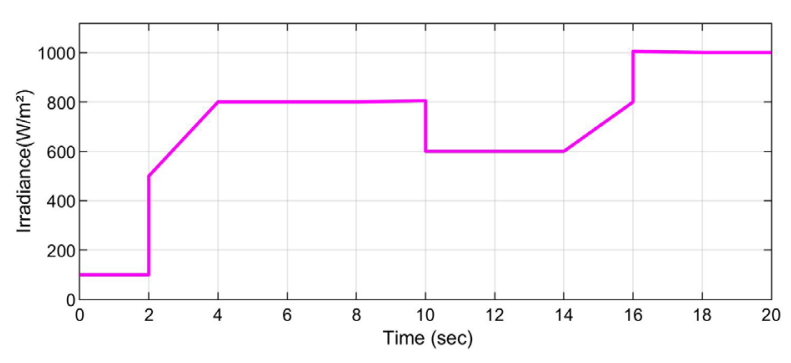

Figure 10. Irradiance profile of the $2,16 \mathrm{kw}$ PV array

The used battery in the first test is an $100 \mathrm{AH}, 48 \mathrm{~V}$ LeA battery bank and it consists of a set of four $12 \mathrm{~V}$ Le-A batteries connected in series, the state of charge (SoC) is set to $99.8 \%$. Moreover, the reference voltage for the FLC 2 regultor is fixed at Vref $=55.5 \mathrm{~V}$ for the absorption stage, while in the second test,we used two $12 \mathrm{~V}$ Le-A batteries connected in series. The figures 12 and 13 present the performance of the studied Le-A batteries at the standard test condition STC, where the variation of current,SoC and voltage are presented.

The figure 12 shows the change of the voltage, current and $\mathrm{SoC}$ of the five Le-A batteries associated in series, where the temperature and solar irradiance are fixed

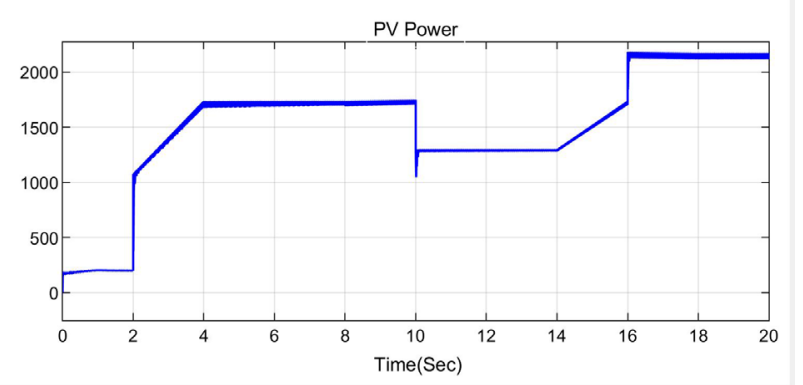

Figure 11. The extracted power of the $2,16 \mathrm{kw}$ PV array
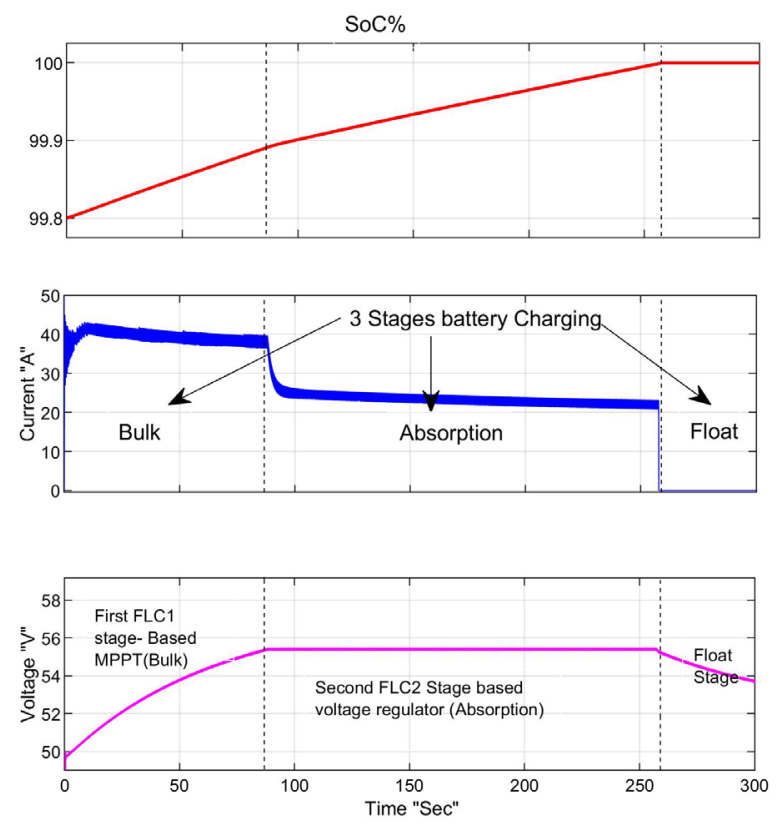

Figure 12. Le-A Battery performance of the first test

in $25^{\circ} \mathrm{C}$ and $1000 \mathrm{~W} / \mathrm{m}^{2}$. The discussed three stages charging levels are clearly seen In case of the test based on five Le-A batteries, for the first state shown in the figure 12 where $0 \mathrm{~s}<\mathrm{t}<84 \mathrm{~s}$, The proposed controller operates in the MPPT stage. As a result, the battery absorbs all of the power provided by the PV array, thus, when the battery SoC is under $100 \%$ and the battery voltage is lower than $\mathrm{Vb}$-ab then the charging process operates in the bulk stage. When the battery voltage achieves $\mathrm{V}_{b-a b}=55,5 \mathrm{~V}$ after 84 seconds, the charger switches to the absorption charging level based regulated voltage. In this stage, the power provided by the PV array is decreased to maintain the regulated voltage in the absorption mode operation and to reduce the amount battery's current. At $262 \mathrm{sec}$ when the SoC achieves $100 \%$, the proposed controller moves to the float operation level in which the battery voltage decreases to the floating voltage where $\mathrm{V}_{b-f l}=52.4 \mathrm{~V}$.

Figure 13, shows the parameters of the battery bank in the case of the second test, where the the battery bank is composed of two Le-A batteries coupled in series at the 

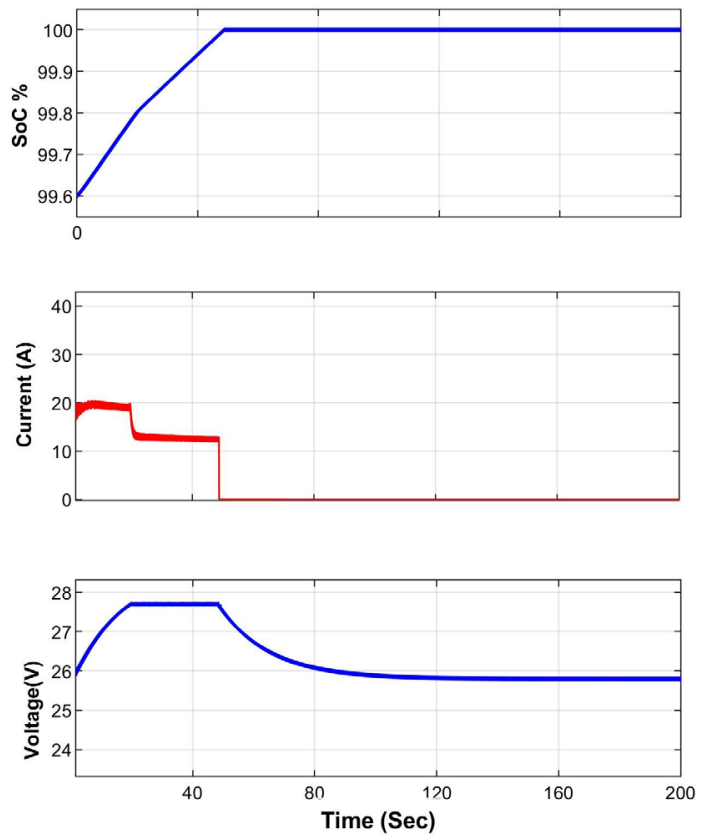

Figure 13. The Le-A Battery performance of the second test

standard test conditions. The three stages charging mode are clearly seen. The initial SoC is set to $99.6 \%$. In the first phase, the controller performs in the FLC1 (MPPT mode) until that the battery voltage reaches the reference voltage $\mathrm{V}_{b-a b}=27.7 \mathrm{~V}$ at $\mathrm{t}=18 \mathrm{~s}$. When $18 \mathrm{~s}<\mathrm{t}<52 \mathrm{~s}$, the battery voltage is regulated at the absorption voltage $27.7 \mathrm{~V}$ where the battery current is automatically decreased via FLC2. The battery SoC reaches $100 \%$ at $52 \mathrm{~s}$, then the FLC2 adjust the reference voltage again at $\mathrm{V}_{b-f l}=25.9 \mathrm{~V}$, in this phase, to prevent self-discharge and to guarantee $100 \%$ of SoC, only a limited current is provided.

\section{Conclusion}

In this paper, an intelligent lead acid battery charger controller is proposed for PV application. Pursuant to the charging operation mode, the proposed technique allows the system to operate in the perfect conditions. Thus, the controller is a combination of two fuzzy controllers(MPPT and the charge controller). The results have shown that the FLC1 based MPPT methodology delivers an outstanding performance in comparison with the classical approaches $\mathrm{P} \& \mathrm{O}$ and IncCon in terms of the efficiency and rising time, while the second fuzzy controller FLC2 operates as a voltage charge regulator. Furthermore, The findings of simulations were presented for various battery sizes where the three-states charging mode are clearly seen. This strategy ensures that the battery operates within a safe voltage range in the proper mode of the three-stage battery charging. The suggested charging technique decreases the restricted charging time while also increases the battery's lifespan.

\section{References}

[1] C. Ehret, S. Piller, W. Schroer and A. Jossen, "Stateof-charge determination for lead-acid batteries in PVapplications." Sixteenth European Photovoltaic Solar Energy Conference. Routledge, (2020).

[2] T. Esram, P. Chapman, "Comparison of Photovoltaic Array Maximum Power Point Tracking Techniques", IEEE Transactions on Energy Conversion, 22, 439-449 (2007).

[3] N. A. Kamarzaman, C.W. Tan, "A Comprehensive Review of Maximum Power Point Tracking Algorithms for Photovoltaic Systems", Renewable and Sustainable Energy Reviews, 37, 585-598 (2014).

[4] M. Salimi, "Practical implementation of the Lyapunov based nonlinear controller in DC-DC boost converter for MPPT of the PV systems," Sol Energy, vol. 173, no. February, pp. 246-255, (2018).

[5] A. Alice Hepzibah and K. Premkumar, "ANFIS current-voltage controlled MPPT algorithm for solar powered brushless DC motor based water pump," Electr Eng, vol. 102, no. 1, pp. 421-435, (2020).

[6] D. P. Hohm and M. E. Ropp, "Comparative Study of Maximum Power Point Tracking Algorithms", Progress in Photovoltaics: Research and Applications, vol. 11, pp. 47-62, (2002)

[7] M. R. Rezoug, R. Chenni, and D. Taibi, "Fuzzy logicbased perturb and observe algorithm with variable step of a reference voltage for solar permanent magnet synchronous motor drive system fed by direct-connected photovoltaic array," Energies, vol. 11, no. 2, (2018)

[8] S. Marhraoui, "Fuzzy Logic-Integral Backstepping Control for PV Grid-Connected System with Energy Storage Management," Int J Intell Eng Syst, vol. 13, no. 3, (2020).

[9] K.V.Hari Prasad, CH.Uma Maheswar Rao," Design And Simulation Of A Fuzzy Logic Controller For Buck \& Boost Converters", International Journal of Advanced Technology \& Engineering Research, (2012).

[10] B. Bendib, F. Krim, H. Belmili, M. F. Almi, and S. Boulouma, "Advanced fuzzy MPPT controller for a stand-alone PV system," Energy Procedia, vol. 50, pp. 383-392, (2014).

[11] M.A. Hasan, S.K.Parida, "An Overview of solar photovoltaic panel modeling based on analytical and experimental viewpoint". Renewable and Sustainable Energy Reviews, Vol. 60, pp. 75-83, (2016).

[12] R. K. Singh, A. Kumar, and B. K. Naick, "Optimised Solar Power Fed Induction Motor Drive for Water Pumping Application Along with Load,' iEECON 2018 - 6th Int Electr Eng Congr, pp. 1-4, (2018)

[13] N. Yildiran and E. Tacer, "Identification of photovoltaic cell single diode discrete model parameters based on datasheet values," Sol Energy, vol. 127, pp. 175-183,(2016).

[14] R. Patil, and A. Harsha "Comparitive analysis of fuzzy based MPPT for buck and boost converter topologies for PV application." 2017 International Conference On Smart Technologies For Smart Nation (SmartTech- 
Con). IEEE, (2017).

[15] A. Selmani, A. Ed-Dahhak, M. Outanoute, A. Lachhab, M. Guerbaoui, and B. Bouchikhi, "Performance evaluation of modelling and simulation of lead acid batteries for photovoltaic applications," Int. J. Power Electron. Drive Syst., vol. 7, no. 2, pp. 472-480, (2016).

[16] J. Meng, D. I. Stroe,M. Ricco, G. Luo and R. Teodorescu, "A simplified model-based state-of-charge estimation approach for lithium-ion battery with dynamic linear model." IEEE Transactions on Industrial Electronics 66.10 (2018).

[17] Y. Triki, A. Bechouche, H. Seddiki and D. O. Abdeslam, "A Smart Battery Charger Based on a Cascaded
Boost-Buck Converter for Photovoltaic Applications," IECON 2018 - 44th Annual Conference of the IEEE Industrial Electronics Society, (2018).

[18] M. Guerbaoui, A. Ed-Dahhak,Y. ElAfou, A.Lachhab,L. Belkoura,and B. Bouchikhi. "Implementation of direct fuzzy controller in greenhouse based on labview." International journal of electrical and electronics engineering studies, (2013).

[19] L. Elmahni, L. Bouhouch, A. Moudden, "Smart management of a photovoltaic pumping station - Located in the Agadir region", Int. J. Innov. Appl. Stud., 18, 4, pp. 1216-1227, (2016). 